\title{
Corrosion Susceptibility and Functionally Graded Properties of Ti-35Nb-4Sn Alloy Processed by Laser Remelting
}

\author{
Juliane Ribeiro da Cruz ${ }^{a}{ }^{\circledR}$, Milton Sérgio Fernandes de Lima ${ }^{b}$, Rodnei Bertazzolic \\ ${ }^{a}$ Instituto Tecnologico de Aeronautica (ITA), Departamento de Engenharia Mecânica, Praça Marechal \\ Eduardo Gomes, 50, 12228-900, São José dos Campos, SP, Brasil \\ ${ }^{b}$ Instituto de Estudos Avancados (IEAv), Divisão Fotônica, Trevo Cel Av José Alberto Albano do \\ Amarante, 01, 12228-001, São José dos Campos, SP Brasil \\ ' Universidade Estadual de Campinas (UNICAMP), Faculdade de Engenharia Mecânica, \\ R. Mendeleyev, 200, 13083-860, Campinas, SP Brasil
}

Received: June 26, 2019; Revised: September 4, 2019; Accepted: January 12, 2020

\begin{abstract}
The effect of laser remelting on the corrosion susceptibility and mechanical properties of Ti-35Nb-4Sn (mass\%) alloy is investigated across the remelted track profile. In comparison to the cold-rolled microstructure of base metal, recrystallization of heat affected zone (HAZ) improved plastic energy absorption and pitting corrosion resistance, by the reduction of active sites for pit nucleation. In fusion zone, however, passivation was compromised by the formation of dendritic microstructure with $\mathrm{Sn}$ enriched interdendritic region, where preferential pitting corrosion occurred. Fusion zone was the most anodic region and presented a corrosion potential difference of $35 \mathrm{mV}$, in comparison to the adjacent and most cathodic HAZ. Electrochemical impedance analysis showed that spontaneous passivation was most effective in base metal, that developed a thicker and more compact passive film. Local increase in elastic modulus and microhardness of fusion zone shows that laser remelting is a viable processing route for the manufacturing of biomaterials with functionally graded properties.
\end{abstract}

Keywords: $\beta$-phase Ti-35Nb-4Sn alloy, Laser welding, Low Young's modulus, Functionally graded material, Electrochemical microcell.

\section{Introduction}

It is known that metallic implants with high elastic modulus can shield the bone from mechanical stresses, which eventually leads to bone resorption, implant loosening and surgery revision ${ }^{1}$. Efforts to minimize stress shielding caused by the elastic modulus mismatch between human bone (10-30 GPa) and currently used implant materials, such as the duplex $\alpha+\beta$ Ti6Al4V $(110 \mathrm{GPa})$, resulted in the development of body-centered cubic $\beta$ - Ti alloys with low elastic modulus, typically below $80 \mathrm{GPa}^{1}$. Ti-35Nb-4Sn (wt $\%$ ) is among these alloys and has one of the lowest values of Young's modulus reported, about $40 \mathrm{GPa}^{1}$. However, to achieve such low elastic modulus, proper chemical composition and thermomechanical processing is necessary ${ }^{2}$. Regarding chemical composition, low interstitial levels is necessary, along with $\mathrm{Nb}$ additions of about $35 \mathrm{wt} \%$, to meta-stabilize Ti- $\beta$ phase at room temperature ${ }^{3}$, and $\mathrm{Sn}$ additions, to suppress or retard precipitation of the non-compact hexagonal $\omega$ phase, that notably increase the elastic modulus. As Sn additions were found to decrease the corrosion resistance ${ }^{4,5}$, alloys with smaller tin content are also being studied, such as Ti35 Nb and $\mathrm{Ti} 35 \mathrm{Nb} 2 \mathrm{Sn}^{6}$. In these other alloys, the elastic modulus is strongly dependent on the thermomechanical processing and can reach up to $110 \mathrm{GPa}$, after few hours aging due to precipitation of $\omega$ and hexagonal close-packed $\alpha$ phases $^{6}$. Regarding thermomechanical processing, solubilization

Email: juliane.rcruz@gmail.com treatment of stiff precipitates ( $\omega$ and $\alpha$ ), followed by quenching and severe cold work must also be performed ${ }^{7,8}$. A decrease in elastic modulus of $\mathrm{Ti}-\mathrm{Nb}$ alloys has been observed for cold rolling reduction over $50 \%{ }^{8}$ and $65 \%{ }^{9}$ and is usually associated to the formation of strain-induced $\alpha$ "-martensite, with base-centered orthorhombic structure.

Besides alloy design, laser processing has been extensively studied as a tool to improve the performance of biomedical implants ${ }^{10}$. Among these applications are the use of laser surface texturing to improve osteointegration ${ }^{11,12}$ and laser nitriding to improve wear and corrosion resistance ${ }^{13}$. Laser processing is also being studied for the manufacturing of components with functionally graded elastic modulus ${ }^{14-16}$. This is of particular interest in bone plates for fracture healing, in which overall low elastic modulus is desired to minimize stress shielding while local high elastic modulus is necessary to stabilize the fracture site. Tailoring of elastic modulus in Ti-Nb alloys has been achieved by laser additive manufacturing using graded chemical composition ${ }^{14}$ and by localized aging treatment ${ }^{17,18}$. However, despite the advantages of laser processing, the imposed thermal cycle induces metallurgical transformations that may cause undesired local change in materials properties ${ }^{10}$. When the material is remelted, three characteristic zones can be identified: the unaffected base metal, whose original properties remain the same, the heat affected zone (HAZ), where transformations as tempering, recrystallization and grain growth may occur, 
and the fusion zone, where quenching, phase transformations, dendritic solidification and metallic vaporization can occur, among others. These zones are typically called weld zones. As laser is a high energy density process, weld zones resulting from laser processing can be short-ranged and micro characterization techniques are necessary for precise characterization of each weld zone ${ }^{19}$.

In this work, the effect of laser remelting in microstructure, mechanical and electrochemical properties of Ti35 Nb4Sn alloy is assessed. Microhardness, elastic modulus, and elastic and plastic energy absorption of each weld zone (determined by nanoindentation) are discussed as a function of microstructure and chemical composition. Electrochemical properties are determined using a novel capillary-based microcell setup, in which microcapillary consists in a laser perforated PET (polyethylene terephthalate) mask. Differences in corrosion resistance parameters, pitting susceptibility and characteristic of passive film formed in the initial 96h of immersion in electrolyte solution are discussed as a function of microstructure and chemical composition changes for each weld zone.

\section{Materials and Methods}

A high purity charge of Ti-35Nb-4Sn (wt\%) was arc melted under analytical argon atmosphere for at least 10 times. The ingot was cold rolled to a $9 \mathrm{~mm}$ thickness, ultrasonically degreased with acetone, encapsulated in a quartz tube under argon atmosphere, homogenized for the $24 \mathrm{~h}$ at $1000^{\circ} \mathrm{C}$, and water quenched at $0^{\circ} \mathrm{C}$. Homogenized ingot was cold rolled along ten passes from 9 to $3 \mathrm{~mm}$ (66\% reduction), chemically stripped $\left(1 \mathrm{HF}: 1 \mathrm{HNO}_{3}: 5 \mathrm{H}_{2} \mathrm{O}\right)$ and ultrasonically cleaned.

A plate sample of about $25 \times 15 \times 3 \mathrm{~mm}$ was laser remelted at the transverse direction. An Yb-fiber laser with Gaussian beam, $\mathrm{M}^{2}$ factor of 9 , wavelength of $1080 \mathrm{~nm}, 50 \mu \mathrm{m}$ of focal beam radius and $160 \mathrm{~mm}$ of focal distance was used. Remelting was performed with $1000 \mathrm{~W}$ of power, scan speed of $10 \mathrm{~mm} . \mathrm{s}^{-1}$ and a defocusing distance of $5 \mathrm{~mm}$. A protective helium flow of $101 . \mathrm{min}^{-1}$ was provided. The beam radius and power density at the defocused plane were $313 \mu \mathrm{m}$ and $324 \mathrm{~kW} / \mathrm{cm}^{2}$, respectively.

The cross-section of laser remelted track was subjected to metallographic preparation by cold mounting, grinding up to 1200 grit and polishing with 1 and $0.3 \mu \mathrm{m}$ alumina and $0.04 \mu \mathrm{m}$ colloidal silica. For microstructure analysis, surface was etched with Kroll solution ( $3 \mathrm{ml} \mathrm{HF}, 6 \mathrm{ml} \mathrm{HNO}_{3}$ and $91 \mathrm{ml} \mathrm{H}_{2} \mathrm{O}$ ). The solidification microstructures were investigated by optical microscopy (OM), scanning electron microscopy (SEM) and electron backscatter diffraction (EBSD), with an indexing rate of $91 \%$. The electron microscopy work has been performed with FEI/THERMO Quanta 650 FEG available at LNNano, Campinas. Phase determination was carried out by X-ray diffraction (XRD) analysis on cross section of base metal and fusion zone, covering an area of $2 \times 2 \mathrm{~mm}$. A multi detector equipment with 255 channels, $\mathrm{Cu} \mathrm{K} \alpha$ radiation, $40 \mathrm{~mA}$ and $40 \mathrm{kV}$, parallel $\mathrm{x}$-ray lenses and $2 \times 2 \mathrm{~mm}$ crossed slits were used. Samples were scanned from 30 to $90^{\circ}$, with a step size of about $0.0131^{\circ}$ per channel (active length of $3.3473^{\circ}$ ), and a step time of $100 \mathrm{~s}$. Measurements of the full width at half maximum (FWHM) of gaussian fittings of different diffraction peaks were used to compare lattice distortion between base metal and weld zone.
The chemical composition of base metal, heat affected zone and fusion zone were analyzed at the cross-section of the weld by energy-dispersive x-ray spectroscopy (EDS), after metallographic preparation, in areas of about $150 \times 150 \mu \mathrm{m}$. To investigate possible atmospheric contamination during laser processing, samples of about $100 \mathrm{mg}$ of base metal and weld zone (fusion zone and heat affected zone) were stripped in $1 \mathrm{HF}: 1 \mathrm{HNO}_{3}: 5 \mathrm{H}_{2} \mathrm{O}$ solution, ultrasonically cleaned in distilled water and analyzed for oxygen and nitrogen content in LECO TC500 analyzer.

Vickers microhardness mapping of the weld zone was performed on the cross-section of the weld, under $100 \mathrm{gf}$ load, every $100 \mu \mathrm{m}$ in both longitudinal and transversal directions. Vickers microhardness profile was determined from the center of the weld to the base metal as an average of three rows with 44 indentations each, with a spacing of three times the length of the indentation diagonal. Elastic modulus profile was determined by instrumented nanoindentation and calculated from load-displacement curves, according to the method developed by Oliver and Pharr ${ }^{20}$. Two rows with 19 indentations each were performed from the center of the weld to the base metal. Maximum load of $0.5 \mathrm{gf}$, pause of $10 \mathrm{~s}$, and loading and unloading rates of $1000 \mathrm{mN} \cdot \mathrm{min}^{-1}$ were applied.

The electrochemical response of different weld zones was examined in $\mathrm{NaCl}$ solution by linear potential scan voltammetry and impedance spectroscopy using an innovative three-electrode microcell, Figure 1. A pseudo-reference electrode consisting of a tungsten thread with a diameter of $125 \mu \mathrm{m}$, oxidized for a hundred cycles in $0.1 \mathrm{~mol}^{\mathrm{dm}} \mathrm{dm}^{-3}$ $\mathrm{H}_{2} \mathrm{SO}_{4}$ solution from 0.954 to $1.854 \mathrm{~V} v$ s. saturated $\mathrm{Ag} / \mathrm{AgCl}$, was used $^{21}$. This oxidized tungsten electrode is hereafter symbolized by $\mathrm{W} / \mathrm{W}_{\mathrm{x}} \mathrm{O}_{\mathrm{y}}$. A platinum thread with diameter of $100 \mu \mathrm{m}$ was used as the counter electrode. The electrolyte consisted in deaerated saline solution of $0.8 \% \mathrm{NaCl} \mathrm{pH} 7.4$ (same concentration and $\mathrm{pH}$ as simulated body fluid - SBF solution $)^{22}$. The electrolyte volume was a drop of about $30 \mu \mathrm{L}$. The open circuit potential (OCP) of the oxidized tungsten electrode $v s . \mathrm{Ag} / \mathrm{AgCl}$ was of $-176 \mathrm{mV}$ in $\mathrm{NaCl}$ electrolyte solutions. The analysis area was of about $0.04 \mathrm{~mm}^{2}$ (radius of $113 \mu \mathrm{m}$ ), delimited by a laser drilled adhesive PET (Polyethylene terephthalate) mask. All tests were conducted inside a Faraday cage with controlled relative humidity of $72 \pm 3 \%$, to minimize electrolyte vaporization. Before every new polarization, specimen was re-polished with $40 \mathrm{~nm}$ colloidal silica, for at least $5 \mathrm{~min}$. Specimen was then ultrasonically cleaned with water, washed with isopropyl alcohol, acetone and distilled water, and dried with compressed $\mathrm{N}_{2}$ flow.

Linear potential scan voltammetry of micro areas within the weld zones was carried from -0.6 to $0.7 \mathrm{~V}\left(v s\right.$. W/W $\left.\mathrm{O}_{v}\right)$, after $30 \mathrm{~min}$ OCP stabilization, with a scan rate of $1 \mathrm{mV} / \mathrm{s}$ and acquisition every $0.2 \mathrm{mV}$. Corrosion potential and current density were determined considering data recorded within Tafel window (with $\chi^{2}$ test smaller than $10^{-18}$ ). A large area linear potential scan voltammetry comprising all weld zones was performed using the same parameters up to $0.8 \mathrm{mV} v s$. $\mathrm{Ag} / \mathrm{AgCl}$, for SEM investigation of pitting location. Before SEM analysis, specimen was etched with Kroll solution. Electrochemical impedance spectroscopy (EIS) of 


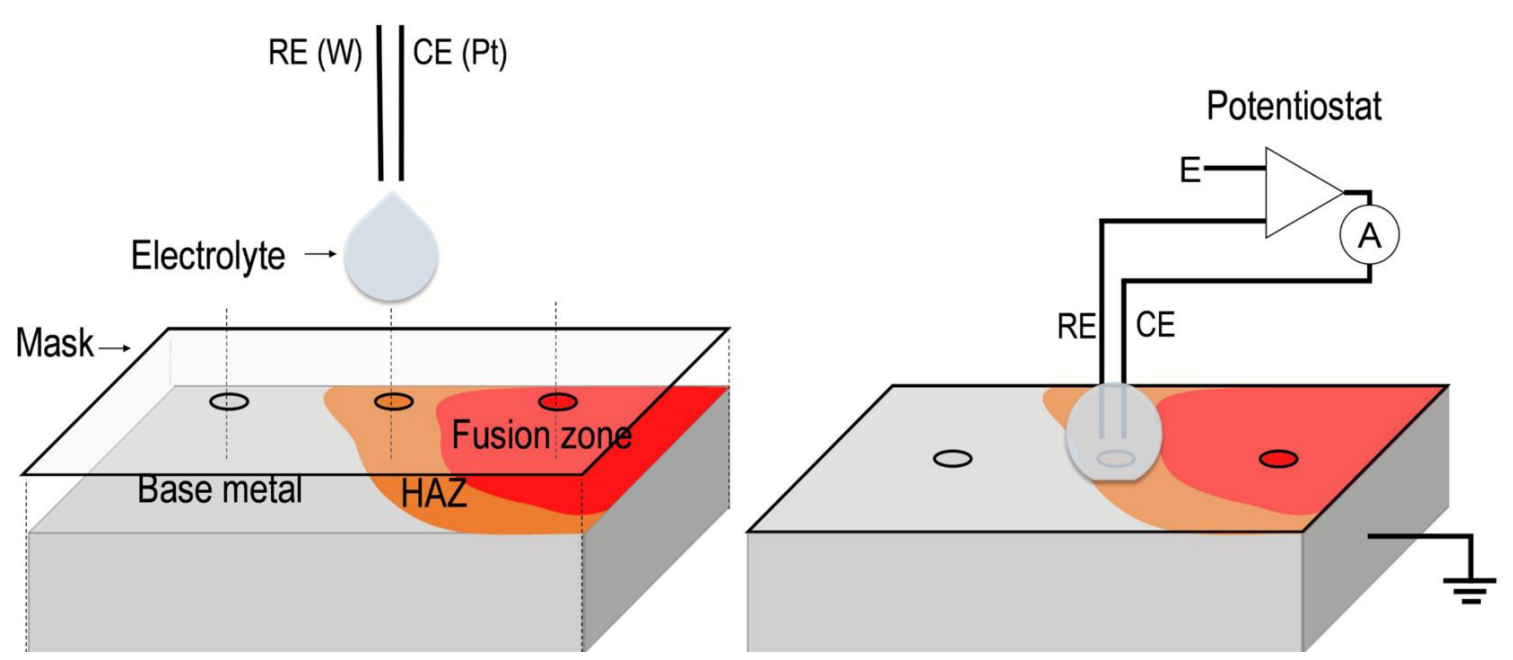

Figure 1. Scheme of the three-electrode microcell set up used in electrochemical characterization of micro areas within the weld zones

micro areas was recorded at open circuit potential from $10^{5}$ to $10^{-1} \mathrm{~Hz}$ with $10 \mathrm{mV}$ amplitude, after $0,24,48,72$ and $96 \mathrm{~h}$ of immersion in electrolyte solution. Analysis of an equivalent electric circuit was also performed to better understand the performance of the surface. The obtained parameters are discussed together with Nyquist and Bode diagrams.

\section{Results and Discussion}

\subsection{Microstructure and Mechanical Properties of Weld Zones}

Microscopy analysis showed that laser induced significative microstructure changes at the cross-section of the remelted track. Fusion zone solidified with a dendritic structure and a keyhole shape, Figure 2a. A fusion zone with keyhole shape typically forms when a condition of successive laser reflections stablishes at the weld pool walls, increasing energy absorption ${ }^{23}$. EBSD band contrast image shown in Figure $2 \mathrm{~b}$ clearly shows recrystallization at HAZ and grain growth toward fusion zone. SEM images of the weld zones are shown in Figure $2 \mathrm{c}$ to $2 \mathrm{f}$. Although the microstructure of fusion zone is essentially dendritic, different solidification modes were identified. At fusion boundary, columnar dendritic grains developed following an epitaxial growth from HAZ parent grains, Figure 2e. As temperature gradient diminished towards the weld centerline, solidification was less directional and resulted in the formation of polygonal grains with equiaxed dendrites, Figure $2 \mathrm{f}$.

EDS measurements of average chemical composition shown in Table 1 did not accuse any significant difference from one weld zone to another. However, in fusion zone, significant partition of elements occurred within the dendritic structure, Figure 3. While the dendritic core had higher content of $\mathrm{Nb}(39.4 \mathrm{wt} \% \pm 0.7)$ and lower content of

Table 1. Average chemical composition of the alloy determined by EDS in different weld zones (wt\%)

\begin{tabular}{ccc}
\hline $\mathrm{Ti}$ & $\mathrm{Nb}$ & $\mathrm{Sn}$ \\
\hline $59.4 \pm 0.1$ & $36.4 \pm 0.2$ & $4.2 \pm 0.1$ \\
\hline
\end{tabular}

$\operatorname{Sn}(3.8 \pm 0.2)$, the interdendritic region had lower content of $\mathrm{Nb}(33.1 \mathrm{wt} \% \pm 0.8)$ and higher content of $\mathrm{Sn}(4.6 \mathrm{wt} \% \pm 0.1)$. In non-equilibrium solidification conditions, such as weld bead solidification, the high cooling rates suppress chemical composition homogenization by atomic diffusion. As seen in $\mathrm{Ti}-\mathrm{Nb}$ phase diagram ${ }^{24}$, the solidification temperature increases with $\mathrm{Nb}$ additions up to $2500{ }^{\circ} \mathrm{C}$, for pure $\mathrm{Nb}$. On the other hand, Sn additions tend to decrease solidification temperature due to its low melting point $230^{\circ} \mathrm{C}$. This way, it is coherent that, under fast cooling, clusters with high $\mathrm{Nb}$ and low Sn content would solidify first, serving as nuclei for dendrites growth. At the same time, the remaining liquid with low $\mathrm{Nb}$ and high $\mathrm{Sn}$ content would solidify last, at the interdendritic region.

Besides $\mathrm{Nb}$ and $\mathrm{Sn}$ partition, another difference in chemical composition of fusion zone was observed. Interstitial analysis showed that, from base metal to weld zone, oxygen content increased from $0,158 \%$ to $0,179 \%$ while nitrogen content nearly doubled, from $0,068 \%$ to $0,122 \%$. The increase in interstitial content might have been caused by insufficient shielding of the melting pool against atmospheric contaminations, during laser processing. The distribution of these interstitials in the weld zone could not be resolved by EDS, as their content is below the minimum required for reliable detection.

The increase in interstitials content had important implications in mechanical properties of fusion zone. Figure 4a shows the 3D microhardness maps of keyhole crosssection, where great increase in hardness occurred, despite the expected reduction in hardness due to recrystallization and grain growth, shown in Figure 2b. XRD analysis at Figure 5 reveals that this abrupt increase in microhardness is not associated with phase transformations, as both base metal and fusion zone regions presented $\beta$-structure. While microhardness of polygonal equiaxed dendritic grains, found in central regions of the keyhole, ranged from about $270 \mathrm{HV}_{0.1}$ to $330 \mathrm{HV}_{0.1}$, microhardness at fusion boundaries reached a maximum of $396 \mathrm{HV}_{0.1}$. EDSD analysis provided evidence that the higher microhardness at fusion boundaries are related to higher degree of lattice distortions at this zone. Figure $4 \mathrm{~b}$ shows EBSD band slope image of the keyhole, where regions 

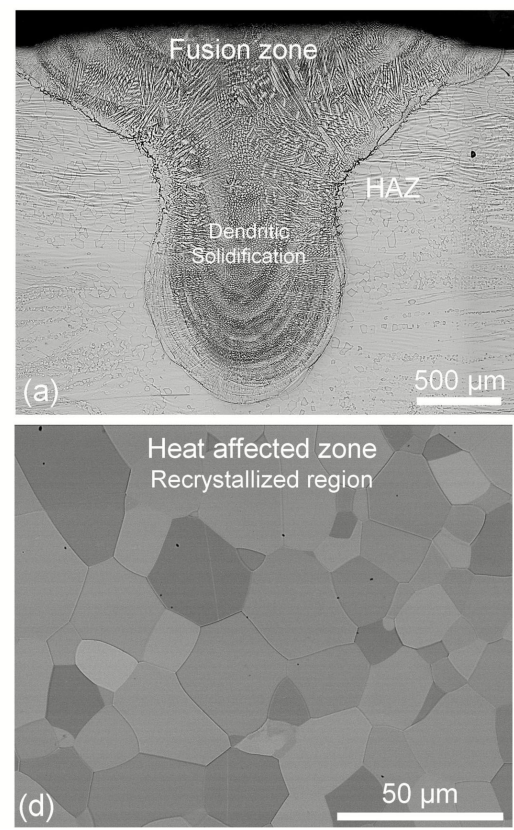
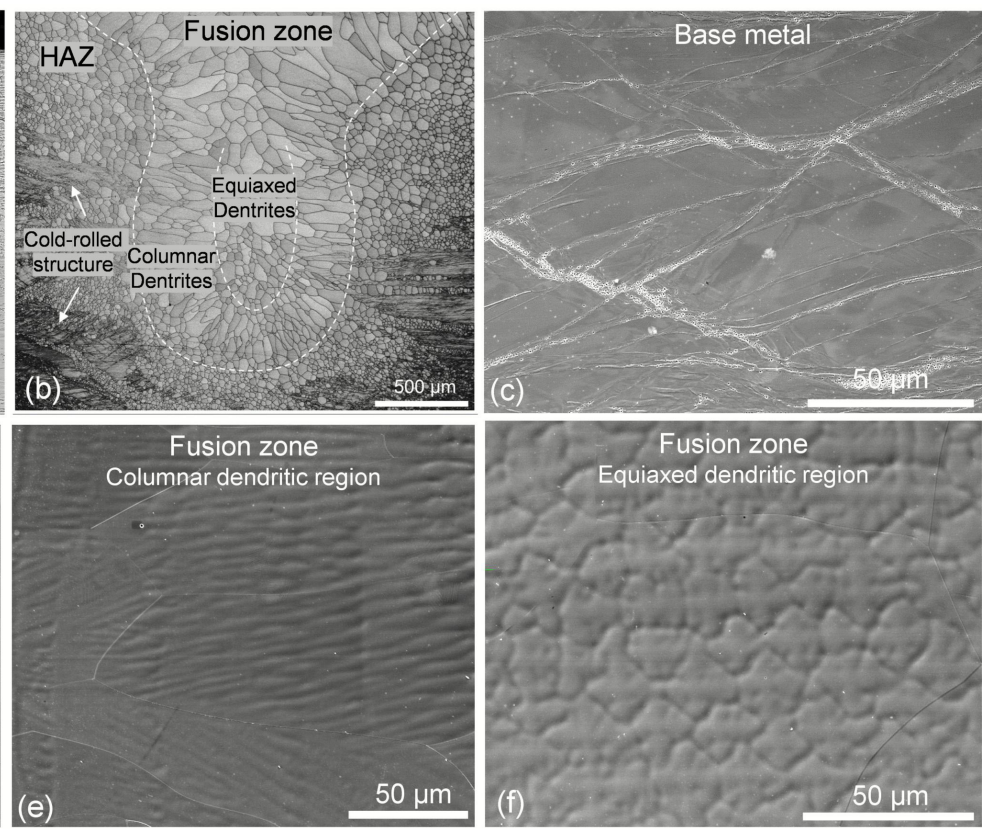

Figure 2. Microstructure of laser processed Ti35Nb4Sn alloy: (a) optical microscopy of weld cross-section showing dendritic solidification and the keyhole shape of the remelted track. (b) EBSD band contrast image showing recrystallization and grain growth from base metal toward fusion zone. Dashed-line of (b) roughly separates microstructure of weld zones. SEM images of (c) cold-rolled base metal, (d) recrystallized HAZ, (e) columnar dendritic solidification at fusion zone boundary and (f) equiaxed dendritic solidification at fusion zone centerline
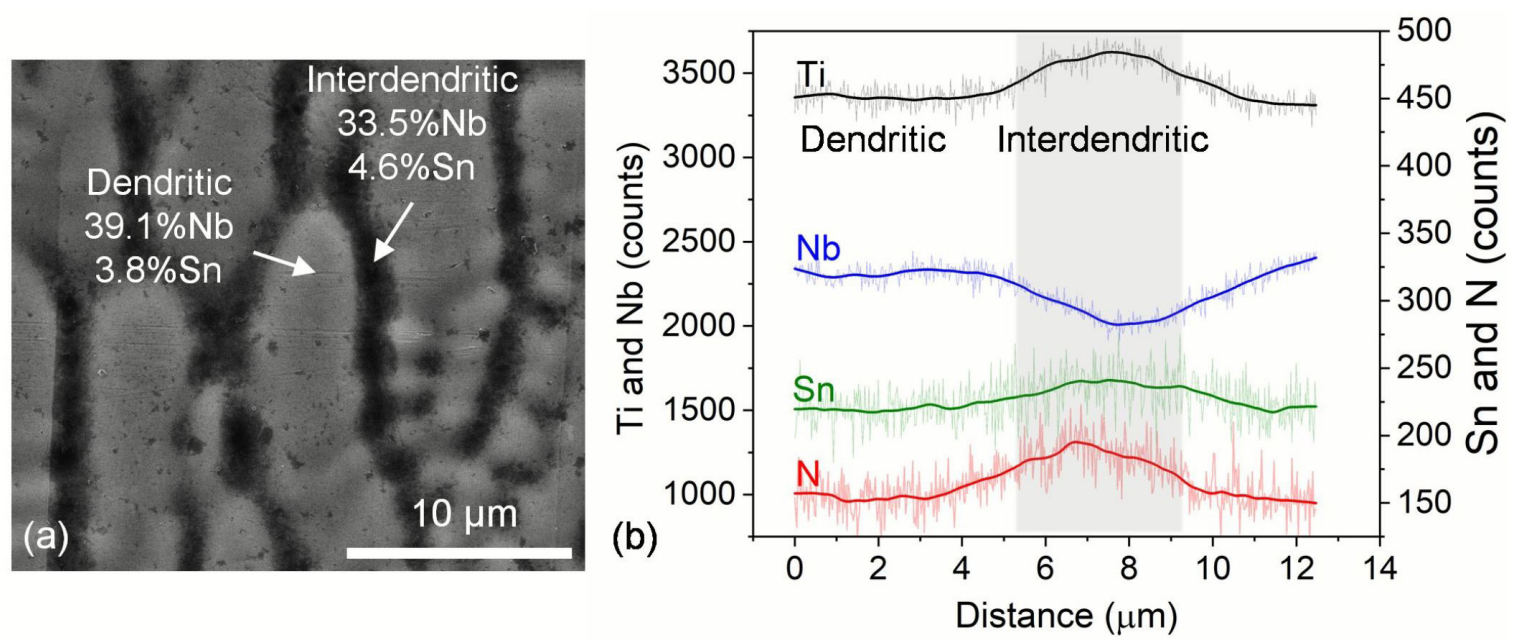

Figure 3. EDS chemical composition across dendrites in fusion zone, revealing dendritic core enriched with $\mathrm{Nb}$. Sn content is $0.8 \mathrm{wt} \%$ higher at interdendritic region

with poorer crystallinity are darker than those with higher crystallinity. Although crystallinity of fusion zone and HAZ is partially improved with recrystallization, significant lattice distortion can be seen along fusion boundary. These results are in full agreement with those reported by Turner et al. ${ }^{25}$, in which residual stresses induced by the solidification of a keyhole laser weld are higher in fusion zone than in HAZ or base metal and are maximum at the very edge of the weld bead. Therefore, the higher content of interstitials seems to be a primary cause for the abrupt increase in microhardness of fusion zone, while the higher concentration of lattice distortions is a secondary cause. Together, these two factors account for the broadening of XRD peaks from base metal to fusion zone regions, as observed by the increase in full width at half maximum (FWHM) measurements shown in Figure 5. The correlation of diffraction line broadening and lattice parameters distortions is well stablished ${ }^{26}$ and has been used to assess the performance of welds ${ }^{27}$.

Figure 6 shows load-displacement curves representative of each weld zones, showing an increase in plastic deformation in HAZ and a decrease in fusion zone, in comparison to base metal. Figure 7 shows the elastic modulus and microhardness profile from fusion zone to cold-rolled base metal. Recrystallization promoted a gradual decrease in 

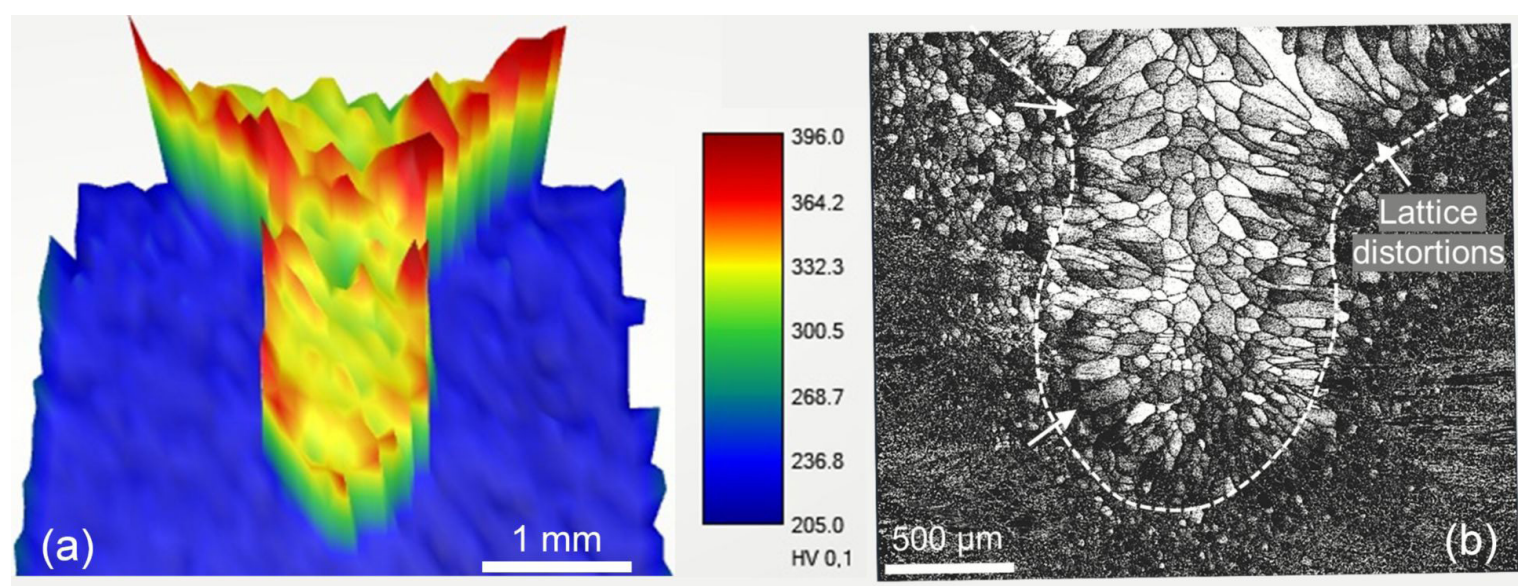

Figure 4. (a) 3D microhardness maps on keyhole cross-section showing abrupt increase in microhardness of fusion zone, in comparison to base metal and heat affected zone, especially at fusion boundaries. (b) EBSD band slope image on keyhole cross-section showing darker regions on fusion zone boundaries with higher lattice distortion

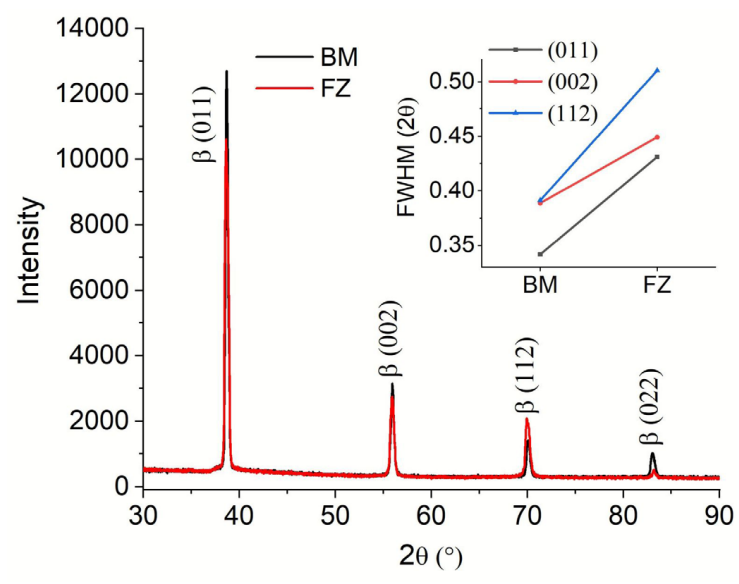

Figure 5. XRD analysis of base metal and fusion zone regions showing no phase transformations with laser remelting. Broadening of XRD peaks (full-width at half-maximum) at fusion zone due to higher lattice distortions

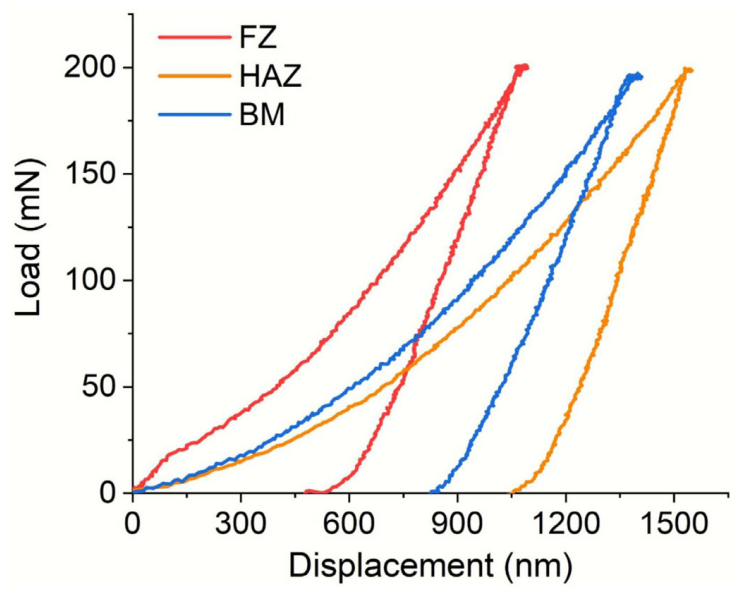

Figure 6. Load-displacement curves representing each of the weld zones: fusion zone, heat affected zone and base metal

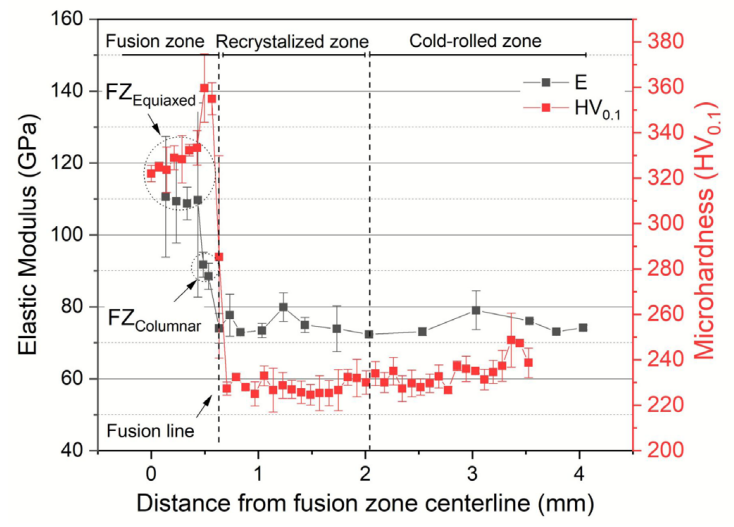

Figure 7. Elastic modulus and microhardness profile from fusion zone centerline to base metal. Hardness decreased at heat affected zone due to recrystallization. Hardness and elastic modulus increased at fusion zone due to higher interstitial content

microhardness from base metal toward HAZ but had no significant effect on the elastic modulus. This shows that no further reduction in elastic modulus was obtained with the $66 \%$ reduction cold rolling. Although progressive decrease in elastic modulus could be expected for rolling reductions over $50 \%{ }^{8}$, maximum reductions were only achieved after severe plastic deformation $(\sim 90 \% \text { rolling reduction })^{2,8}$. As elastic modulus reduction is usually associated to the formation of strain induced $\alpha$ "-martensite, this result is coherent with XRD measurements that did not accuse its presence in the cold-rolled base metal, Figure 5. While both interstitial content and lattice distortions affect microhardness, elastic modulus is little affected by dislocation densities, but strongly affected by interstitials content. In $\beta$-Ti alloys, elastic modulus is most notably increased by nitrogen ${ }^{28}$ than by oxygen additions ${ }^{29}$. In $\alpha+\beta$ alloys, however, oxygen seems to have a more significant effect ${ }^{30}$. Curiously, the elastic modulus was smaller at fusion boundaries than at fusion zone centerline. This can be associated to the faster solidification of fusion boundaries from the pre-existing solid interface (HAZ), 
followed by the diffusion of interstitials to the remaining liquid in fusion zone center line, that solidifies last ${ }^{31}$.

Figure 8 shows elastic, plastic and total energy absorption profile of the remelted track. In comparison to base metal, total energy absorption of HAZ increased in about $10 \%$ while that of fusion zone was reduced in about $14 \%$, as result of differences in plastic and elastic energy absorption of each zone. In fusion zone and base metal, plastic deformation was restrained by the presence of interstitials elements and of abundant dislocations generated by work-hardening, respectively. This accounted for a reduction in plastic energy absorption, that was about $25 \%$ smaller in fusion zone than in base metal. On the other hand, recrystallization allowed HAZ to recover its ductility. Maximum plastic energy absorption was found in this region, that was improved in about $24 \%$ in comparison to base metal. Progressive increase in toughness from base metal toward the recrystallized zone indicates that some annealing occurred within the cold-rolled

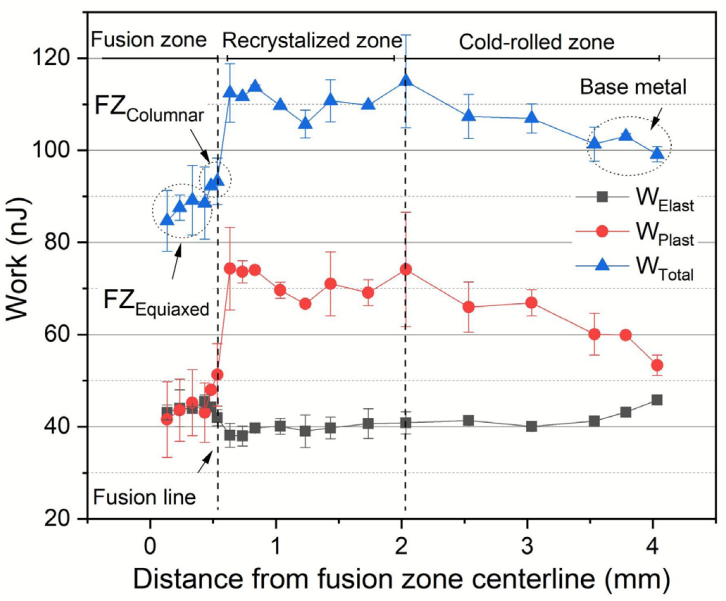

Figure 8. Elastic, plastic and total work on the remelted profile. Increase in plastic and decrease in elastic energy absorption of HAZ with annealing and recrystallization. Decrease in plastic and increase in elastic energy absorption of fusion zone with increase in interstitials content

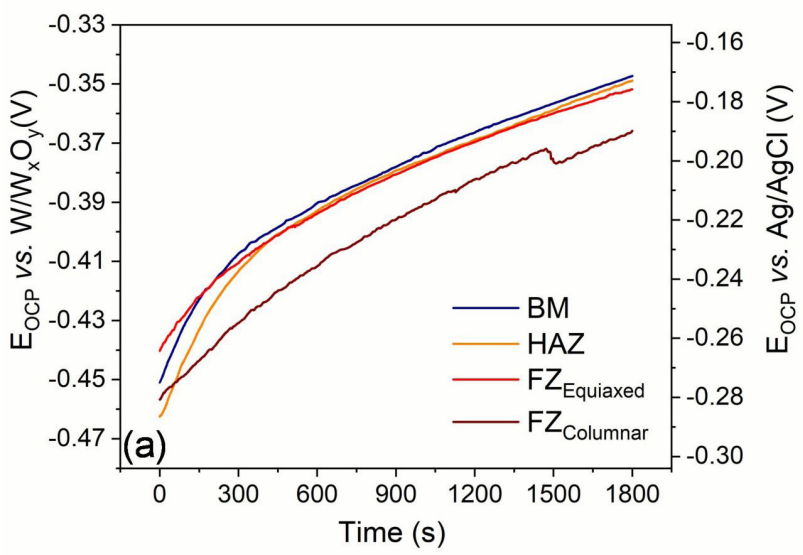

region. This annealed zone can also be considered as part of HAZ. Interestingly, recrystallization softening reduced the elastic energy absorption of HAZ in about $9 \%$, in comparison to base metal. In fusion zone, this was compensated by interstitial strengthening and elastic energy absorption was reestablished. Rather than compromising the resilience of the alloy, studies show that additions of nitrogen and oxygen can increase the critical stress for slip and improve the shape memory effect and the superelasticity of Ti-Nb alloys ${ }^{32,33}$. The shape memory effect of $\mathrm{Ti}-\mathrm{Nb}$ alloys requires specific thermomechanical processing and was not explored in this present study.

Results show that the selected laser processing parameters allowed the formation of a structure with functionally graded elastic modulus, ranging from a relatively low value of $75 \mathrm{GPa}$ up to $110 \mathrm{GPa}$, which is close to the elastic modulus of currently used implant materials ${ }^{1}$. The development of Ti-Nb implants with graded elastic modulus has been investigated by several researchers ${ }^{14,15,17,18,34,35}$. Recently, Lima et al. have used laser additive manufacturing using different chemical compositions to manufacture bone plates with graded elastic modulus from $70 \mathrm{GPa}$ to $115 \mathrm{GPa}$, where hardness ranged from 270 to $350 \mathrm{HV}_{0.1}{ }^{14}$. Also, Lopes et al. have produced a graded elastic modulus femoral hip stem using localized aging by electro-magnetic induction heating, where elastic modulus ranged from $65 \mathrm{GPa}$ to $110 \mathrm{GPa}$ and micro hardness from $225 \mathrm{HV}_{0.1}$ to $420 \mathrm{HV}_{0.1}{ }^{17}$. In this context, laser remelting with controlled additions of oxygen or nitrogen stands out as a potential route for manufacturing of components with functionally graded elastic modulus in a fast and simple way.

\subsection{Electrochemical response of weld zones}

Figure 9 shows open circuit potential and polarization curves of weld regions in $\mathrm{NaCl}$ physiological solution. Table 2 summarizes results from Tafel analysis of polarization curves. The shift in OCP curves toward more positive values in Figure 9a shows that the weld zones undergo spontaneous passivation in the electrolyte solution.

Results show that both equiaxed and columnar regions of fusion zone are the least resistant to polarization. Table 2 shows that fusion zone is anodic in comparison to base metal

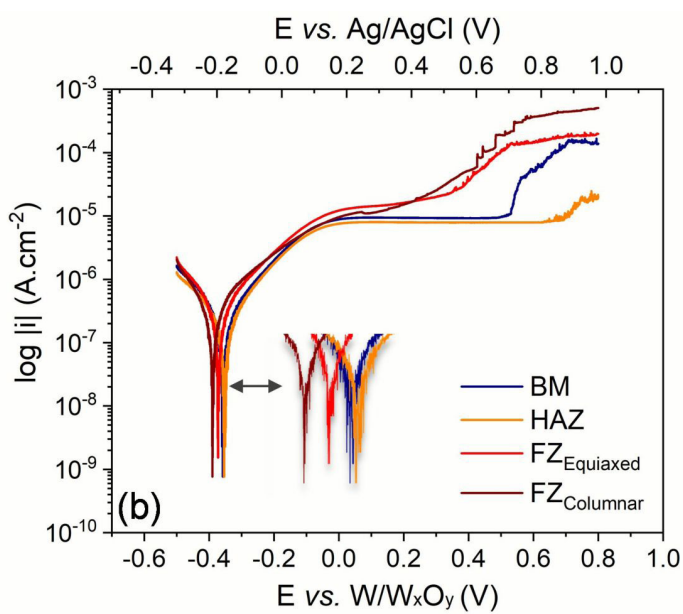

Figure 9. (a) Open circuit potential showing spontaneous passivation of all weld zones in physiological saline solution. (b) Polarization curves showing that passivation is more effective in $\mathrm{HAZ}$ and BM and that fusion zone is more anodic and more susceptible to pitting 
and HAZ, and that potential difference between the adjacent $\mathrm{HAZ}$ and the fusion boundary (FZ columnar) reaches up to $35 \mathrm{mV}$. Besides, fusion zone also presents lower polarization resistances and higher corrosion current densities. On the other hand, both base metal and HAZ presented higher corrosion resistant with more positive corrosion potential and broad passivation plateaus. The difference in the performance of BM and HAZ seems to be related to the surface activity intrinsic of each microstructure. In comparison to the recrystallized structure, the cold-rolled structure has dislocations and other imperfections that increase its free-energy ${ }^{36}$, and account for a higher surface activity. This facilitates the occurrence of surface reactions and may be the cause for the higher current densities of the cold-rolled structure. Furthermore, the cold-rolled structure of base metal also has more active sites that facilitate pitting nucleation, causing a reduction in pitting potential. Therefore, the lower current densities and higher pitting potential of HAZ are associated to its effective passivation under anodic polarization and to its lower surface activity, that delay surface reactions and pitting nucleation. Regarding the performance of fusion zone, one of the reasons for its inferior corrosion resistance in the higher content of $\mathrm{Sn}$ in the interdendritic regions. It has been reported that the increase in $\mathrm{Sn}$ content in $\mathrm{Ti}-\mathrm{Nb}-\mathrm{Sn}$ alloys is followed by an increase the dissolution rate of the passive film ${ }^{4,5}$ that is proportional to the applied potential and is critical above $4 \mathrm{wt} \%{ }^{4,5}$. Another factor that can account for the decrease in corrosion resistance of fusion zone is the coarse-grained microstructure ${ }^{37}$. A review from Ralston and Birbilis on the impact of grain sizes on corrosion properties observed that, when the media promotes passivation, grain refinement increases corrosion resistance while grain coarsening reduces $\mathrm{it}^{37}$. This is associated to the formation of a more compact passive layer upon the refined structure and a more open passive layer upon the coarse-grained microstructure, as illustrated by Gollapudi ${ }^{38}$. This is coherent with SEM analysis of pitting location, that indicated the occurrence of multiple pitting in fusion zone, preferentially at Sn enriched interdendritic regions, Figure $10 \mathrm{~b}$ and c. Elongated pitting at base metal and HAZ can be associated to chemical composition inhomogeneities, aligned during cold rolling. Unlike $\mathrm{Sn}, \mathrm{Nb}$ content is not critical. Studies on the corrosion resistance of $\mathrm{Ti}-20 \mathrm{Nb}$ and $\mathrm{Ti} 40 \mathrm{Nb}$ alloys in $\mathrm{NaCl}$ physiological solutions showed that both alloys presented similar corrosion potentials and that $\mathrm{Ti}-40 \mathrm{Nb}$ had higher stability and pitting resistance ${ }^{39}$. This could be rather related to the more refined and active structure of Ti-20Nb alloy, that is martensitic, than to $\mathrm{Nb}$ content itself. As $\beta$-phase remained stable even in interdendritic region with lower content of $\mathrm{Nb}, \mathrm{Nb}$ fluctuations $(\sim 32-40 \mathrm{wt} \%)$ are not expected to have any detrimental effect in the corrosion resistance. Similarly, studies on ion implantation of $\mathrm{O}^{40}, \mathrm{~N}^{41}$ and laser surface nitriding ${ }^{13}$ suggest that alloying with these elements can improve corrosion resistance of Ti alloys, by shifting the corrosion potential to more positive values and by decreasing corrosion current density. Although the higher content of interstitial alone could not improve the corrosion resistance of fusion zone in comparison to BM and HAZ, due to the detrimental effects of Sn fluctuations and grain coarsening, it might have caused the higher corrosion potential of equiaxed dendritic region, in comparison to columnar dendritic region. As discussed before, the higher elastic modulus of equiaxed dendritic region may be associated to diffusion of interstitials to this region during solidification.

Table 2. Parameters adjusted from Tafel region: Corrosion potential $\mathrm{E}_{\text {corr }}$, corrosion current density $\mathrm{i}_{\text {corr }}$, polarization resistance $\mathrm{R}_{\mathrm{p}}$, pitting potential $\mathrm{E}_{\text {pit }}$ and passive current dendity $\mathrm{i}_{\text {pass }}$

\begin{tabular}{|c|c|c|c|c|c|}
\hline & $\mathrm{E}_{\text {corr }} *(\mathrm{mV})$ & $\mathrm{i}_{\text {corr }}\left(\mu \mathrm{A} \mathrm{cm}^{-2}\right)$ & $\mathrm{R}_{\mathrm{p}}\left(\mathrm{k} \Omega \mathrm{cm}^{2}\right)$ & $\mathrm{E}_{\mathrm{pit}} *(\mathrm{mV})$ & $\mathrm{i}_{\text {pass }}\left(\mu \mathrm{Acm}^{-2}\right)$ \\
\hline $\mathrm{BM}$ & $-358(-182)$ & 0.43 & 121 & $530(706)$ & 9.3 \\
\hline HAZ & $-355(-179)$ & 0.32 & 148 & $695(871)$ & 7.9 \\
\hline $\mathrm{FZ}_{\text {Equiaxed }}$ & $-374(-198)$ & 0.46 & 97 & - & - \\
\hline $\mathrm{FZ}_{\text {Columnar }}$ & $-390(-214)$ & 0.55 & 92 & - & - \\
\hline
\end{tabular}

$* v s . \mathrm{W} / \mathrm{W}_{\mathrm{x}} \mathrm{O}_{\mathrm{y}}(v s . \mathrm{Ag} / \mathrm{AgCl})$
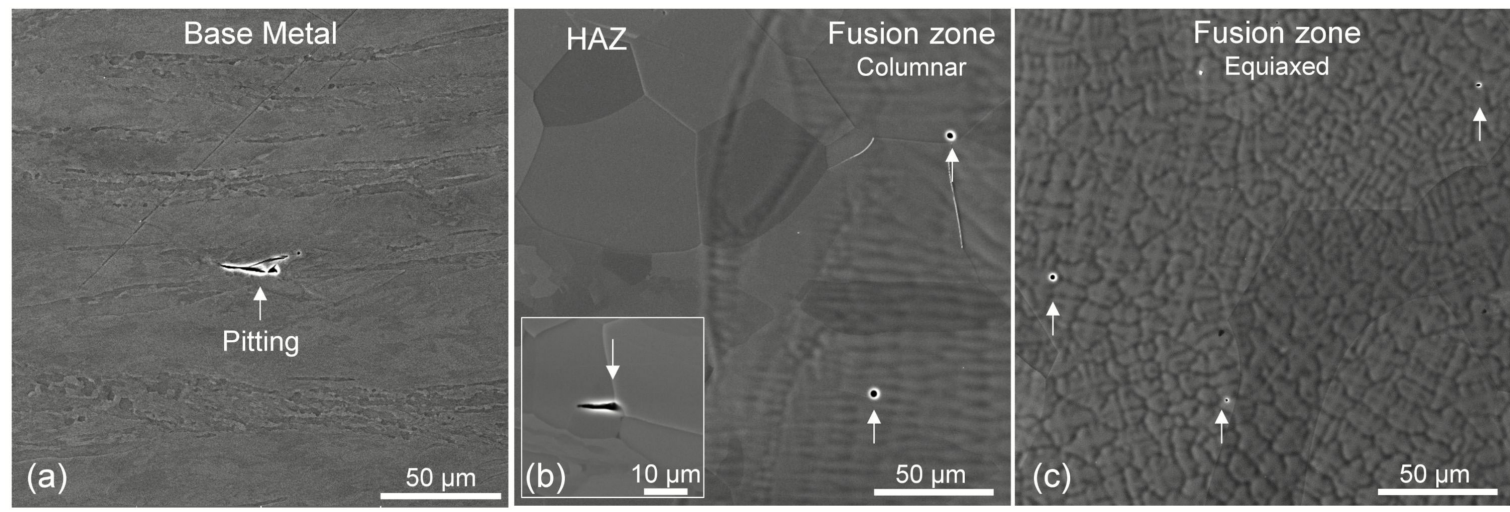

Figure 10. Pitting morphology and location after simultaneous anodic polarization of all weld zones up to $0.8 \mathrm{mV}$ vs. Ag/AgCl. Elongated pitting in (a) base metal and (b) HAZ, and multiple pitting corrosion in (b) fusion boundary and fusion zone, with preferential pitting at Sn enriched interdendritic regions 
Figure 11 shows Bode and Nyquist curves for each weld zone after $0,2448,72$ and $96 \mathrm{~h}$ of immersion in $0.8 \% \mathrm{NaCl}$ solution. Graphs are presented in the same scale for direct comparison. Results show that the impedance of the weld zones progressively increased with the immersion time and reached maximum values in base metal (Figure 10b), followed by HAZ (Figure 10d) and fusion zone (Figure 10f), respectively. Phase angle of weld zones increased with the immersion time and was more pronounced in base metal than in HAZ and fusion zone. In HAZ, phase angle was slightly reduced for higher frequencies. In fusion zone, increase in phase angle occured for a shorter range of frequencies. To better understand the performance of each weld zone, EIS curves were fitted to the equivalent electric circuit shown in Fig. 11b. The obtained parameters are presented in Figure 12 together with OCP measurements. Figure $12 \mathrm{f}$ allows direct comparison of the phase angles of weld zones after $96 \mathrm{~h}$.

Results show that base metal was the most noble region and that a thicker and more compact passive film developed in this zone. The lower CPE values shown in Figure 12b indicate that current flow through the film is smaller in this location and this is most likely caused by an increase in the thickness of the film ${ }^{42}$. Besides, the higher values of $n$ exponent in this region, Figure $12 \mathrm{c}$, indicate that the capacitive behavior of the film is closer to the ideal and less current leakage flows through it. This suggest that the passive layer in this region is more compact and has with fewer defects. Base metal also developed higher charge transfer resistances throughout the test, Figure 12d, and solution resistance on all cases can be considered negligible, Figure 12e. Consequently, base metal presented the highest values of impedance and phase angles after $96 \mathrm{~h}$ immersion, Fig. 12f. On the other hand, although HAZ developed the most effective passive layer under anodic polarization, the passive layer spontaneously formed was less effective than that of base metal, as suggested by the intermediate values of OCP, Figure 12a. Results show that
HAZ presented a higher CPE (Figure 12b) and smaller value of $n$ exponent (Figure 12c), which indicate that the thickness and the integrity of the film were reduced, in comparison to base metal. The increase in current leakage through the film as shown by the lower $n$ exponent is most likely the cause of phase angle reduction at high frequencies, when impedance is governed by the capacitive component of the interface. However, HAZ presented a relatively high charge transfer resistance in comparison to fusion zone (Figure 12d), which granted an improved performance at low frequencies, when impedance is governed by the resistive component. The improved performance of base metal in comparison to $\mathrm{HAZ}$ is consistent with prior reports ${ }^{37,38}$ that more refined microstructures undergo most effective passivation than the coarser ones. Although spontaneous passivation of HAZ was reduced in comparison to that of base metal, results indicate that anodization is a viable route for growth stable passive layer in this region. Fusion zone presented the least effective spontaneous passivation during immersion in electrolyte solution as represented by the lower values of OCP (Figure 12a), phase angle and impedance (Figure 12f). This region also developed the lowest charge transfer resistance (Figure 12d), and a thinner and less compact film in comparison to base metal, as shown by the higher values of CPE (Figure 12b) and relatively smaller values of $\mathrm{n}$ exponent (Figure 12c). Although fusion zone developed similar polarization resistance and corrosion current density as those of other weld zones, Table 2, which stands for a relatively high corrosion resistance, the higher concentration of $\mathrm{Sn}$ in interdendritic region and the coarse-grained microstructure had a detrimental effect in the passivation of this region. Future strategies to mitigate corrosion in this region should consider using alloys with lower content of Sn and optimized laser processing parameters for obtention of more refined microstructure.
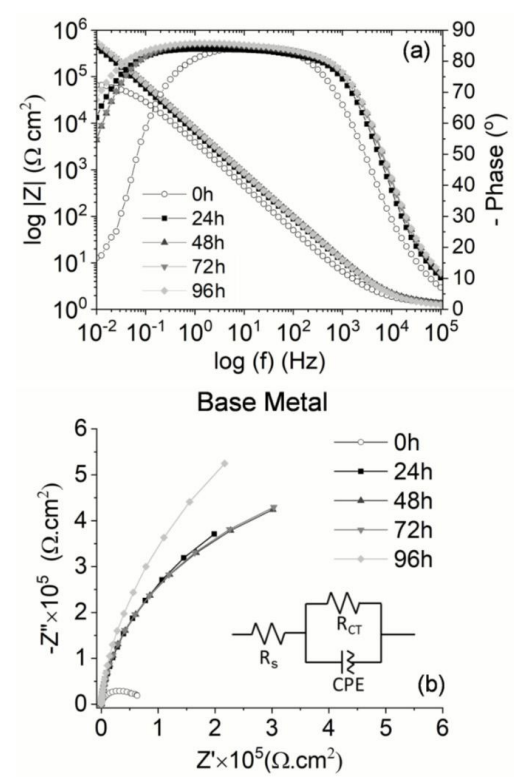
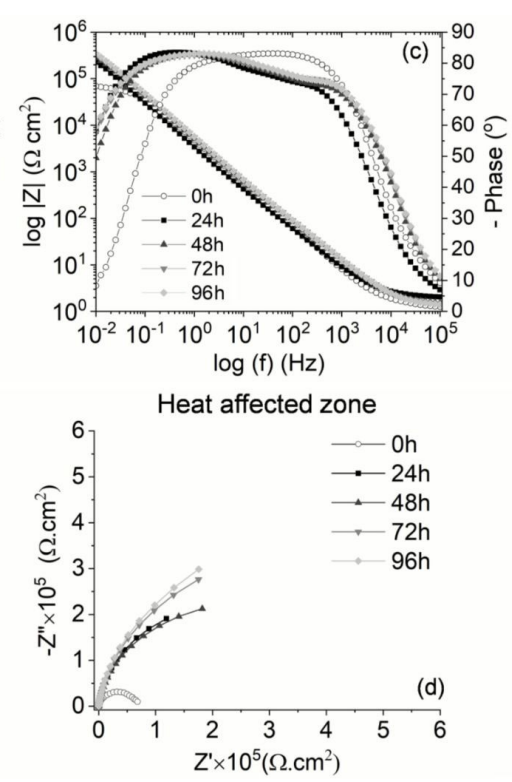

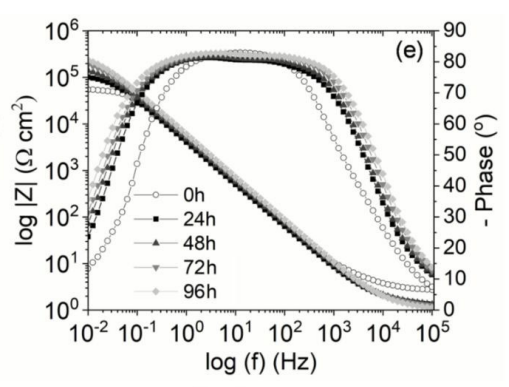

Fusion zone

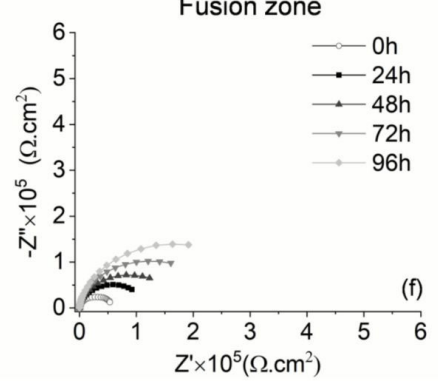

Figure 11. Bode (on top) and Nyquist (on bottom) plots of base metal (a,b), heat affected zone (c,d) and fusion zone (e,f) after $0,24,48,72$ and $96 \mathrm{~h}$ of immersion in $0.8 \% \mathrm{NaCl}$ physiological saline solution 

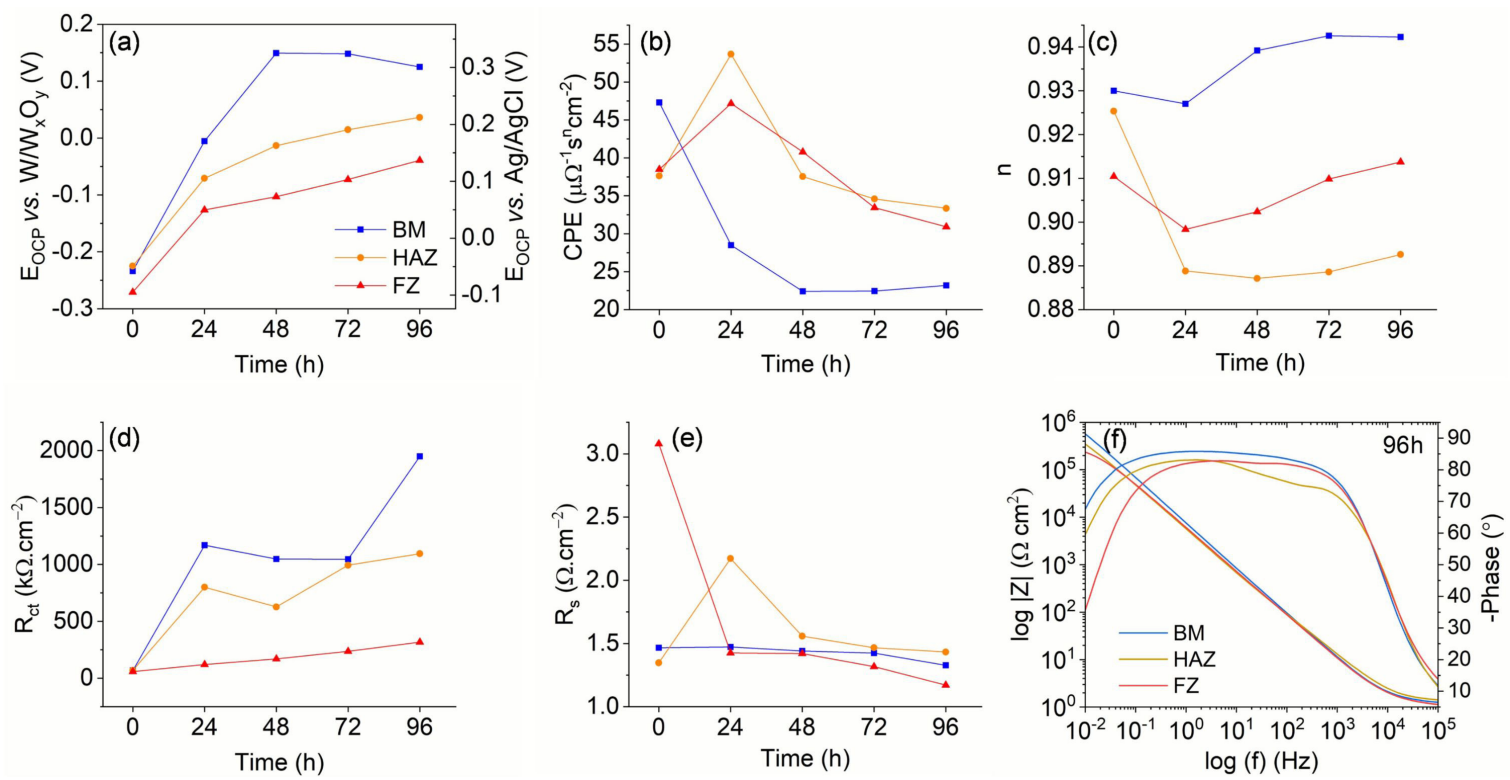

Figure 12. Parameters from EIS measurements of weld zones after 0, 24, 48, 72 and 96h: (a) open circuit potential, (b) constant phase element, (c) n exponent, (d) charge transfer resistance and (e) solution resistance. (f) Direct comparison of Bode graphs of weld zones after $96 \mathrm{~h}$ immersion in $0.8 \% \mathrm{NaCl}$ physiological solution

\section{Conclusions}

Fiber laser remelting was performed on top of a 3 mm-thick $\beta$-type Ti-35Nb-4Sn alloy. Microstructure changes as well as mechanical and electrochemical responses in $\mathrm{NaCl}$ physiological solution were assessed. The main conclusions are presented as follows:

Laser remelting did not cause any phase transformation in the initial $\beta$ structure, but induced recrystallization at heat affected zone. This did not affect the elastic modulus of HAZ, but slightly reduced the microhardness and the elastic energy absorption. On the other hand, recrystallization greatly increased plastic energy absorption in about $25 \%$, in comparison to base metal. HAZ presented clear passivation plateau and higher pitting potential than base metal, whose cold-rolled microstructure provided more active sites for pitting nucleation. On the other hand, impedance analysis showed that spontaneous passivation was more effective in the cold-rolled structure of base metal than in the recrystallized structure of HAZ, where passive layer was thinner and less compact.

Laser remelting induced recrystallization and grain coarsening at fusion zone. This region also presented a dendritic structure, where $\mathrm{Nb}$ partitioned to dendritic core and Sn partitioned to interdendritic region.

Laser processing also induced an increase in the content of oxygen and nitrogen of fusion zone which locally increased microhardness, from about $200 \mathrm{HV}_{0.1}$ to $330 \mathrm{HV}_{0.1}$, and the elastic modulus, from $75 \mathrm{GPa}$ to $110 \mathrm{GPa}$. Fusion boundaries developed higher lattice distortions which contributed for further increase in microhardness up to about $400 \mathrm{HV}_{0.1}$ and resulted in an intermediate elastic modulus of $90 \mathrm{GPa}$. Elastic energy absorption of fusion zone was sustained, but plastic energy absorption was reduced.

The electrochemical performance and passivation of fusion zone was impaired by the higher content of Sn in interdendritic region and by its coarser microstructure. Fusion zone was the most anodic region. Under anodic polarization, it presented a corrosion potential difference of $35 \mathrm{mV}$, in comparison to the adjacent and most cathodic HAZ. Unlike base metal and HAZ, fusion zone did not present a clear passivation plateau and was more susceptible to pitting corrosion, that occurred preferentially at $\mathrm{Sn}$ enriched interdendritic regions. Fusion zone presented the lowest charge transfer resistance and had the least effective passivation in $\mathrm{NaCl}$ physiological solution.

\section{Acknowledgements}

The authors would like to thank FAPESP for research founding Proc. FAPESP 2016/10637-4, CAPES for graduation scholarship, and the LNNano/CNPEM/MCTIC for technical support during electron microscopy work. Special thanks to Dr. Getúlio de Vasconcelos and MSc. Renê Volu for their support with laser drilling, to Eng. Vitor Ribeiro for his support with instrumented nanoindentation analysis, to Dr. Victor Riguetti for his support with x-ray diffraction analysis and to Dr. Vinicius Henriques for his support with interstitials content analysis.

\section{References}

1. Niinomi M, Nakai M. Titanium-based biomaterials for preventing stress shielding between implant devices and bone. Int J Biomater. 2011;1-10. http://dx.doi.org/10.1155/2011/836587.

2. Guo S, Meng Q, Zhao X, Wei Q, Xu H. Design and fabrication of a metastable $\beta$-type titanium alloy with ultralow elastic modulus and high strength. Sci Rep. 2015;5(1). http://dx.doi. org/10.1038/srep14688.

3. Hon Y-H, Wang J-Y, Pan Y-N. Composition/phase structure and properties of titanium-niobium alloys. Mater Trans. 2003;44(11):2384-90. http://dx.doi.org/10.2320/matertrans.44.2384.

4. Dalmau A, Guiñón Pina V, Devesa F, Amigó V, Igual Muñoz A. Electrochemical behavior of near-beta titanium biomedical 
alloys in phosphate buffer saline solution. Mater Sci Eng C. 2015;48:55-62. http://dx.doi.org/10.1016/j.msec.2014.11.036.

5. Pina VG, Dalmau A, Devesa F, Amigó V, Muñoz AI. Tribocorrosion behavior of beta titanium biomedical alloys in phosphate buffer saline solution. J Mech Behav Biomed Mater. 2001;46:59-68. http://dx.doi.org/10.1016/j.jmbbm.2015.02.016.

6. Cremasco A, Lopes ESN, Bertazzoli R, Caram R. Application of coupled substrate aging and $\mathrm{TiO} 2$ nanotube crystallization heat treatments in cold-rolled Ti-Nb-Sn alloys. J Mater Sci. 2016;51(13):6389-99. http://dx.doi.org/10.1007/s10853-0169935-2.

7. Bönisch M, Calin M, Waitz T, Panigrahi A, Zehetbauer M, Gebert A, et al. Thermal stability and phase transformations of martensitic Ti-Nb alloys. Sci Technol Adv Mater. 2013;14(5):55004. http:// dx.doi.org/10.1088/1468-6996/14/5/055004.

8. Matsumoto H, Watanabe S, Hanada S. Microstructures and mechanical properties of metastable $\beta$ TiNbSn alloys cold rolled and heat treated. J Alloys Compd. 2007;439(1-2):14655. http://dx.doi.org/10.1016/j.jallcom.2006.08.267.

9. Hayama AOF, Lopes JFSC, Gomes da Silva MJ, Abreu HFG, Caram R. Crystallographic texture evolution in Ti-35Nb alloy deformed by cold rolling. Mater Des. 2014;60:653-60. http:// dx.doi.org/10.1016/j.matdes.2014.04.024.

10. Vilar R. Laser surface modification of biomaterials. USA: Elsevier; 2016. http://dx.doi.org/10.1016/c2014-0-01731-5.

11. Pou P, Riveiro A, del Val J, Comesaña R, Penide J, Arias-González $\mathrm{F}$, et al. Laser surface texturing of Titanium for bioengineering applications. Procedia Manufacturing. 2017;13:694-701. http:// dx.doi.org/10.1016/j.promfg.2017.09.102.

12. Faeda RS, Tavares HS, Sartori R, Guastaldi AC, Marcantonio E Jr. Evaluation of titanium implants with surface modification by laser beam: biomechanical study in rabbit tibias. Braz Oral Res. 2009;23(2):137-43. http://dx.doi.org/10.1590/s180683242009000200008

13. Chan C-W, Lee S, Smith G, Sarri G, Ng C-H, Sharba A, et al. Enhancement of wear and corrosion resistance of beta titanium alloy by laser gas alloying with nitrogen. Appl Surf Sci. 2016;367:80-90. http://dx.doi.org/10.1016/j.apsusc.2016.01.091.

14. Lima DD, Mantri SA, Mikler CV, Contieri R, Yannetta CJ, Campo KN, et al. Laser additive processing of a functionally graded internal fracture fixation plate. Mater Des. 2017;130:815. http://dx.doi.org/10.1016/j.matdes.2017.05.034.

15. Lin W-S, Starr TL, Harris BT, Zandinejad A, Morton D. Additive manufacturing technology (Direct Metal Laser Sintering) as a novel approach to fabricate functionally graded titanium implants: preliminary investigation of fabrication parameters. Int J Oral Maxillofac Implants. 2013;28(6):1490-5. http:// dx.doi.org/10.11607/jomi.3164.

16. Traini T, Mangano C, Sammons RL, Mangano F, Macchi A, Piattelli A. Direct laser metal sintering as a new approach to fabrication of an isoelastic functionally graded material for manufacture of porous titanium dental implants. Dent Mater. 2008;24(11):1525-33. http://dx.doi.org/10.1016/j. dental.2008.03.029.

17. Lopes ESN, Contieri RJ, Button ST, Caram R. Femoral hip stem prosthesis made of graded elastic modulus metastable $\beta$ Ti Alloy. Mater Des. 2015;69:30-6. http://dx.doi.org/10.1016/j. matdes.2014.11.040.

18. Jung TK, Matsumoto H, Abumiya T, Masahashi N, Kim MS, Hanada S. Mechanical Properties-Graded Ti Alloy Implants for Orthopedic Applications. Mater Sci Forum. 2009;631-632:205-10. http://dx.doi.org/10.4028/www.scientific.net/msf.631-632.205.

19. Abraham GJ, Kain V, Dey GK, Raja VS. Corrosion characterization of laser beam and tungsten inert gas weldment of nickel base alloys: micro-cell technique. Corros Sci. 2015;93:1-8. http:// dx.doi.org/10.1016/j.corsci.2014.12.016.

20. Oliver WC, Pharr GM. Measurement of hardness and elastic modulus by instrumented indentation: advances in understanding and refinements to methodology. JMR. 2004;19(1):3-20. http:// dx.doi.org/10.1557/jmr.2004.19.1.3.

21. Pašti IA, Lazarević-Pašti T, Mentus SV. Switching between voltammetry and potentiometry in order to determine $\mathrm{H}+$ or $\mathrm{OH}-$ ion concentration over the entire $\mathrm{pH}$ scale by means of tungsten disk electrode. J Electroanal Chem. 2012;665:83-9. http://dx.doi.org/10.1016/j.jelechem.2011.11.019.

22. Kokubo T, Takadama H. How useful is SBF in predicting in vivo bone bioactivity? Biomaterials. 2006;27(15):2907-15. http://dx.doi.org/10.1016/j.biomaterials.2006.01.017.

23. Courtois M, Carin M, Le Masson P, Gaied S. A two-dimensional axially-symmetric model of keyhole and melt pool dynamics during spot laser welding. Rev Metall. 2013;110(2):165-73. http://dx.doi.org/10.1051/metal/2013060.

24. Zhang Y, Liu H, Jin Z. Thermodynamic assessment of the Nb-Ti system. Calphad. 2001;25(2):305-17. http://dx.doi.org/10.1016/ s0364-5916(01)00051-7.

25. Turner RP, Panwisawas C, Sovani Y, Perumal B, Ward RM, Brooks JW, et al. An integrated modeling approach for predicting process maps of residual stress and distortion in a laser weld: a combined CFD-FE methodology. Metall Mater Trans, B, Process Metall Mater Proc Sci. 2016;47(5):2954-62. http:// dx.doi.org/10.1007/s11663-016-0742-6.

26. Balzar D. Diffraction line broadening - Nuisance or latticeimperfections fingerprints. Croat Chem Acta. 1996;69:1069-115.

27. Jun T-S, Hofmann F, Hofmann M, Korsunsky AM. Residual stress characterization in $12 \%$-Cr steel friction stir welds by neutron diffraction. J Strain Anal Eng Des. 2012;47(4):203-13. http://dx.doi.org/10.1177/0309324712441433.

28. Carquigny S, Takadoum J, Ivanescu S. Comparative study of nitrogen implantation effect on mechanical and tribological properties of Ti-6Al-4V and Ti-10Zr-10Nb-5Ta alloys. Eur Phys J Appl Phys. 2019;85(2):21301. http://dx.doi.org/10.1051/ epjap/2019180149.

29. Tane M, Hagihara K, Ueda M, Nakano T, Okuda Y. Elasticmodulus enhancement during room-temperature aging and its suppression in metastable Ti-Nb-Based alloys with low body-centered cubic phase stability. Acta Mater. 2016;102:37384. http://dx.doi.org/10.1016/j.actamat.2015.09.030.

30. Lee YT, Welsch G. Young's modulus and damping of Ti$6 \mathrm{Al}-4 \mathrm{~V}$ alloy as a function of heat treatment and oxygen concentration. Mater Sci Eng A. 1990;128(1):77-89. http:// dx.doi.org/10.1016/0921-5093(90)90097-m.

31. Kou S. Welding metallurgy. Hoboken: John Wiley \& Sons, Inc.; 2002. http://dx.doi.org/10.1002/0471434027.

32. Kim JI, Kim HY, Hosoda H, Miyazaki S. Shape memory behavior of Ti-22Nb-(0.5-2.0)O(at\%) biomedical alloys. Mater Trans. 2005;46(4):852-7. http://dx.doi.org/10.2320/matertrans.46.852.

33. Tahara M, Kim HY, Hosoda H, Miyazaki S. Shape memory effect and cyclic deformation behavior Of Ti-Nb-N alloys. Funct Mater Lett (Singap). 2009;2(2):79-82. http://dx.doi. org/10.1142/s1793604709000600.

34. Ataollahi Oshkour A, Talebi H, Seyed Shirazi SF, Bayat M, Yau YH, Tarlochan F, et al. Comparison of various functionally graded femoral prostheses by finite element analysis. ScientificWorldJournal. 2014;1-17. http://dx.doi. org/10.1155/2014/807621.

35. Ganesh V, Ramakrishna K, Ghista DN. Biomed Eng Online. 2005;4(1):46. http://dx.doi.org/10.1186/1475-925x-4-46.

36. Rios PR, Siciliano F Jr, Sandim HRZ, Plaut RL, Padilha AF. Nucleation and growth during recrystallization. Mater Res. 2005;8(3):225-38. http://dx.doi.org/10.1590/s151614392005000300002 .

37. Ralston KD, Birbilis N. Effect of grain size on corrosion: a review. Corros Sci. 2010;66(7):075005-075005-13. http:// dx.doi.org/10.5006/1.3462912.

38. Gollapudi S. Grain size distribution effects on the corrosion behaviour of materials. Corros Sci. 2012;62:90-4. http://dx.doi. org/10.1016/j.corsci.2012.04.040. 
39. Choe H-C, Ko Y-M, Park H-O. Electrochemical behavior of TiN film coated Ti-Nb alloys for dental materials. Met Mater Int. 2006;12(4):365-9. http://dx.doi.org/10.1007/ bf03027555.

40. Ningshen S, Kamachi Mudali U, Mukherjee P, Sarkar A, Barat $\mathrm{P}$, Padhy $\mathrm{N}$, et al. Influence of oxygen ion irradiation on the corrosion aspects of Ti-5\% Ta- $2 \% \mathrm{Nb}$ alloy and oxide coated titanium. Corros Sci. 2008;50(8):2124-34. http://dx.doi. org/10.1016/j.corsci.2008.03.019.
41. Vlcak P, Fojt J, Weiss Z, Kopeček J, Perina V. The effect of nitrogen saturation on the corrosion behaviour of Ti-35Nb-7Zr-5Ta beta titanium alloy nitrided by ion implantation. Surf Coat Tech. 2019;358:144-52. http://dx.doi.org/10.1016/j.surfcoat.2018.11.004 42. Diamanti MV, Bolzoni F, Ormellese M, Pérez-Rosales EA, Pedeferri MP. Characterisation of titanium oxide films by potentiodynamic polarisation and electrochemical impedance spectroscopy. Corros Eng Sci Technol. 2010;45(6):428-34. http://dx.doi.org/10.1179/147842208x373191. 